\title{
Utilization and referral pattern at Sidamo Regional Hospital: A one-year prospective registration study in 1985/86
}

\author{
Bernt Lindtjørn
}

Sidamo Regional Hospital, P.O. Box 70, Yirga Alem, Ethiopia.

Corresponding author: Professor Bernt Lindtjørn, Nordre Toppe 83, 5136 Mjølkeråen, Norway. E-mail: bernt@lindtjorn.no

Key words: $\quad$ Ethiopia, health care coverage, referrals, in-patients, catchment area, hospital utilization 


\begin{abstract}
Hospitals can serve as important complement to Primary Health Care. Periodic reviews of hospital functions are therefore needed. We have reviewed hospital use and referral pattern at a regional hospital in southern Ethiopia. $85 \%$ of admitted patients were from the region, and 2/3 from the local province. The effect of proximity on hospital use is shown but varied for the different patient groups. Patients from the local province were less often referred than patients from the remote provinces. The hospital functions mainly as a local hospital for the Sidamo Province and less as a referral hospital for the other parts of the region. The very large functional catchment area may worsen the local population's access to the hospital.
\end{abstract}

\title{
INTRODUCTION
}

This is a paper I wrote in 1989 while I worked as a doctor at Sidamo Regional Hospital in Yirga Alem in Ethiopia. Today the hospital has been renamed to Yirga Alem Hospital. The article has been presented at local health conferences but has not been published before. I believe it is of historical interest for researchers and policymakers who wish to study the use of health services in the area. I have briefly edited the original paper.

Periodic reviews of health care utilization and referral pattern are instruments to improve performance of health care systems. The few studies on health care use in Ethiopia cover aspects of use, health behaviour and coverage $(1,2)$. Although hospitals are increasingly viewed as support units for the community $(3,4)$, hospital admission data are of limited value for the description of causes of sickness and death in a population $(5,6)$. However, patient characteristics may give some information on the ability of the hospital to provide the service it was intended for.

With this background we have studied admissions to Sidamo Regional Hospital (SRH) in southern Ethiopia. SRH is by the national health plan (in the 1980s) assigned to be the referral hospital for the Sidamo Region. The aims of this study were to evaluate the use of the hospital in relation to catchment area and to examine the referral pattern among admitted patients.

\section{PATIENTS AND METHODS}

Sidamo Regional Hospital (SRH) is located near to Yirga Alem in the Sidamo Region. The hospital has 120 beds, and basic x-ray and laboratory facilities are available. Annually 55000 outpatients (new and repeat visits) and 4500 inpatients receive treatment. The hospital was during the study period staffed by 5 medical doctors and 16 nurses.

\section{Patients}

4797 admitted patients were recorded prospectively during period September 1, 1985 to August 31, 1986. For each patient card number, age, sex, place of residence, institution referred from, ward admitted to, diagnosis, and outcome were recorded. 


\section{Methods}

The main diagnosis was registered using the WHO's intermediary list of 150 causes of morbidity and mortality (7). Utilization rates (number of admissions per 10000 population) were calculated for each province in the Sidamo Region using the 1984 Census (8).

The effects of socioeconomic factors on proximity was examined by drawing a $10 \%$ random sample from admissions during the study period. The representativeness of the sample was confirmed as the variables age, sex, place of residence and diagnostic groups were all within the $95 \%$ confidence limits of the total figures.

\section{Definitions}

Age: As the accurate determination of age poses a problem, age was classified in four groups: 0$4,5-14,15-44$, and over 45 years of age.

Patient's place of residence was recorded by region and awraja. Patients from Sidamo Province were categorized in two groups depending on whether their home place was more or less than 3 hours walking distance from the hospital. This distance corresponds with the limits of Dale Woreda (local administrative unit), in which SRH is located.

Referral Pattern: A patient was registered as being referred if he/she presented with a referral paper from a health institution (health station, health centre, or hospital).

Socioeconomic status: A patient was defined to be poor if he/she presented with a paper from the urban dwellers or peasant association confirming his/her social status.

\section{Data analysis}

Data analysis was with the SPSS/PC+ (SPSS Inc., Chicago, 1983). The Chi-square (with Yate's correction factor) and t-tests were used when appropriate. P-values less than 0.05 were regarded as statistically significant.

\section{Ethical issues}

This is a study that was carried out on routinely collected information at the hospital during the period 1985/86. All patients agreed to be tested as part of routine patient care, and their data were anonymised before being entered into a computer (9). Several paper from the same hospitals were at that time published $[6,8,11,12]$, and the Ethiopian health authorities did not require ethical approval during that period.

\section{RESULTS}

\section{Hospital use and coverage}


$83.1 \%$; 3275 of 3988 the admitted patients were from Sidamo Region. The percentages from the neighbouring regions were Shewa $8.1 \%$, Bale $5.4 \%$, Arsi $3.0 \%$ and other regions $0.4 \% .82 .1 \%$ of those from the Sidamo region lived in the Sidama Province, $37,3 \%$ of whom lived within three hours walking distance and $44.8 \%$ in other parts of the Sidama Province.

Table 1 shows that the admission rates (per 10,000 population) for the Sidamo Region were inversely proportional to distance to the hospital. The admission rates varied from 23 for the Sidama Province to 0.3 for the Wolayta Province. The corresponding admission rates for the other regions were: Arsi $(0,9)$, Bale (2) and Shewa $(0,7)$. Table 1 also shows that more women were admitted from the Sidama Province than from other provinces or regions. This is mainly caused by patients with obstetric and gynaecological diagnosis, which accounted for $44 \%$ of female admissions. The majority of these patients lived in the Sidama Province.

Table 1 Admission rates per 10.000 population for Sidamo Region

\begin{tabular}{lcccc}
\hline Awraja & Admissions & Male/Female & Population & $\begin{array}{c}\text { Admission } \\
\text { rate per } \\
10.000\end{array}$ \\
\hline Sidama & 3275 & 0.81 & 1425000 & 23,0 \\
$\quad$ Dale woreda & 1487 & 0.72 & 248000 & 60,0 \\
$\quad \begin{array}{l}\text { Rest of } \\
\quad \text { Sidama }\end{array}$ & 1788 & 0.90 & 1167000 & 15,3 \\
& & & & \\
Gedeo & 265 & 1.09 & 624000 & 4,2 \\
Jem Jem & 178 & 1.44 & 267000 & 6,7 \\
Borana & 72 & 0.80 & 104000 & 6,9 \\
Arero & 165 & 1.26 & 408000 & 4,0 \\
Wolayta & 33 & 1.54 & 969000 & 0,3 \\
\hline Total & 3988 & 0.92 & 3787000 & 10,5 \\
\hline
\end{tabular}

The urban/rural distribution of patient's place of residence show that $40 \%$ of the patients from the rural areas lived within three hours walking distance from the hospital while only $15 \%$ were from the rural areas when the walking distance was more than 3 hours. In the other provinces in the Sidamo region only $11 \%$ were from the rural areas. 
Table 2 shows that the poor patients admitted to the hospital live closer to the hospital than the other patient groups.

Table 2 Patient place of residence of poor and regular patients.

\begin{tabular}{lccc}
\hline \multirow{2}{*}{ Place of residence } & $\begin{array}{c}\text { All } \\
\text { patients }\end{array}$ & \multicolumn{2}{c}{ Poor patients } \\
\cline { 3 - 4 } & & Observed & Expected \\
\hline Sidama Awraja & & & \\
Walking distance $<3 \mathrm{~h}$ & 109 & 25 & 13 \\
Walking distance $>3 \mathrm{~h}$ & 211 & 27 & 25 \\
& & & \\
Rest of Sidamo Region & 81 & 5 & 10 \\
Other Regions & 80 & 0 & 9 \\
\hline Total & 481 & 57 & 57 \\
\hline
\end{tabular}

O: Observed; E: expected. (Based on total number of admissions). The difference between the observed and expected values are statistically significant $(\mathrm{X} 2=22,74$; D.f. $3 ; \mathrm{p}<0.001)$. The table represents a $10 \%$ random sample of admitted patients.

\section{Referral pattern}

Five hundred and fifty-six patients (314 men and 242 women) were referred. $212(38.3 \%)$ were referred from health stations, $154(27.2 \%)$ from health centres, and 190 (34.2\%) from other hospitals. There were more men $(56,5 \%$ vs $46,8 \% ; \mathrm{X} 2=28,15 ; \mathrm{p}<0,001)$ and less children under 5 years of age $(9,0 \%$ vs $15,1 \% ; \mathrm{X} 2=7,96 ; \mathrm{p}<0,001)$ among the referred patients compared with the non-referred group.

The surgical ward had more referrals than the other wards (Table 3). The diagnosis of referred and non-referred patients shows that more patients with injuries, but less with malnutrition, respiratory tract, gynaecology and obstetrics diseases were referred (Table 4).

Table 3 Referrals and total number of patients by admitting department.

\begin{tabular}{lccc}
\hline Ward & Observed & Expected & $\begin{array}{c}\text { Total } \\
\text { referred }\end{array}$ \\
\hline Surgical ward & 242 & 122 & 1056 \\
Gynaecology \& Obstetrics & 137 & 173 & 1494 \\
Medical ward & 144 & 185 & 1593 \\
Paediatric ward & 33 & 76 & 655 \\
\hline
\end{tabular}

$\mathrm{X} 2=65.81 ; \mathrm{p}<0.0001$, D.F. $=3$

The referred patients stayed longer at the hospital than non-referred patients (10.5 days vs 8.2 
days; $\mathrm{t}=2.75, \mathrm{p}=0.006) .49(8.8 \%)$ of the referred patients died, compared with $249(5.9 \%)$ of the non-referred $(X 2=7,05 ; \mathrm{p}=0,008)$.

Patients from the distant awrajas within the Sidamo Region were more often referred than patients living within the Sidama Province (Table 2). More patients were referred from hospitals than health stations and health centres in the Borana and Gedeo Provinces. However, this tendency did not apply to patients coming from other regions in southern Ethiopia.

Table 4: $\quad$ Referral pattern in relation to main diagnostic groups.

\begin{tabular}{lcccccccc}
\hline \multirow{2}{*}{ Diagnosis } & \multicolumn{2}{c}{ Referred } & \multicolumn{2}{c}{ Non-Referred } & \multicolumn{2}{c}{ Total } & \multirow{2}{*}{ X2 } & \multirow{2}{*}{$\mathrm{p}$} \\
\cline { 2 - 6 } & No & $\%$ & No & $\%$ & No & $\%$ & & \\
\hline Infectious Diseases & 74 & 13.3 & 521 & 12.3 & 595 & 12.4 & \\
Neoplasms & 29 & 5.2 & 159 & 3.7 & 188 & 3.9 & \\
Allergy and malnutrition & 16 & 2.9 & 227 & 5.4 & 243 & 5.1 & 5.75 & $<0.02$ \\
Mental Disorders & 3 & 0.5 & 51 & 1.2 & 54 & 1.1 & & \\
Diseases of Nervous system & 24 & 4.3 & 218 & 5.1 & 242 & 5.0 & & $<0.001$ \\
Cardiovascular Diseases & 12 & 2.2 & 121 & 2.9 & 133 & 2.8 & & $<0.001$ \\
Respiratory Tract Diseases & 12 & 2.2 & 259 & 6.1 & 271 & 5.6 & 13.60 & \\
Gynaecology and Obstetrics & 92 & 16.5 & 1004 & 23.7 & 1096 & 22.8 & 13.70 & $<$ \\
Skin and Subcutaneous tissue & 16 & 2.9 & 147 & 3.5 & 163 & 3.4 & & \\
Congenital Disorders & 2 & 0.4 & 18 & 0.4 & 20 & 0.4 & & $<0.001$ \\
Early Infirm. & 0 & 0.0 & 4 & 0.1 & 4 & 0.1 & & \\
Ill-defined disorders & 22 & 4.0 & 161 & 3.8 & 183 & 3.8 & & \\
Injury & 134 & 24.1 & 398 & 9.4 & 532 & 11.1 & 106.5 & $<$ \\
\hline Total & 556 & 100.0 & 4242 & 100.0 & 4798 & 100.0 &
\end{tabular}

\section{DISCUSSION}

The effect of geographical accessibility and referral on hospital utilization is shown in this study. Admission rates were inversely proportional to distance from the hospital. However, admission rates were in general low, and suggest that hospital facilities are scarce in the province. The effect of proximity is further shown for the rural patients, women and the destitute patients' groups.

This shows that patients attending a hospital form a heterogeneous group with different proximity characteristics for the various patients. This should have implications for applying more appropriate and just approaches for the delivery of health services to the target populations.

This study confirms the findings of Kloos et al that the SRH has a very large catchment area. Many patients outside the Sidamo Region use the hospital (2). Although this may be viewed to be helpful by the individual patient, the effects on the availability of hospital services for the local population may be a negative one. It may thus be appropriate to hypothesize that limited hospital facilities with large catchment areas may worsen the local populations access to hospital services. 
Our study further demonstrates that referrals within the Sidamo Region increase with distance from the hospital. The referral pattern varied between the different awrajas and was mainly influenced by the availability and function of health institutions. The study also showed that the referred patients represented selected groups with regard to sex and diagnostic categories. The referred patients had longer hospital stay and higher mortality rates than the other patients, indicating more serious diseases. However, most of the disease categories among the referred group were related to surgical conditions and less to the major health problems in the communities such as malnutrition, respiratory tract diseases and gynaecological or obstetrical disorders. The referral pattern thus more reflected the patient's ability to be referred and the services at the regional hospital than the true requirement for referrals based on health needs.

To achieve a fairer distribution of health service resources between geographical areas and population groups requires a measure of the relative health needs of populations. The extent of the bias involved can only be assessed if the true distribution of diseases and health care utilization patterns were known. Our study considers health care use from the view of a health institution. Community based studies on the use of the different health care providers would thus be needed. Such studies could provide more information on factors which determine people's access and potential use of health services (10).

\section{References}

1. Hailu M, Mehari WA. Reaching the people: Some issues in the utilization of selected hospitals in Addis Ababa. Ethiop J Health Develop. 1984;1:65-72.

2. Kloos H, Alemayehu E, Assefa D, Hundessa A, Berhanu S, Kebede A, et al. Illness and health behaviour in Addis Ababa and rural central Ethiopia. Soc Sci Med. 1987;9:1003-19. 3. Aga Khan Foundation and WHO. The role of hospitals in primary health care. Geneva: WHO; 1981.

4. WHO. Hospitals and Health for all. Geneva: WHO; 1987.

5. Abdussalam M, Robinson D. Infections from agriculture. Epidemiology and the community control of disease in warm climate countries. Second. London: Churchill Livingstone; 1985. p. 529-41.

6. $\quad$ Nordberg E. The true disease pattern in East Africa - part 2. E Afr Med J. 1983;60:530-5.

7. WHO. International classification of diseases. Geneva: WHO; 1957.

8. Office of The Population and Housing Census Commission. Ethiopia 1984 population and housing census preliminary report, Vol. 1, No. 1. Addis Ababa, Ethiopia, Office of the Population and Housing Census Commission,. 1984.

9. Lende S, Lindtjørn B. Sykehus i utviklingsland. Erfaringer fra Sidamo Regional Hospital i Sør-Etiopia. Tidsskrift for den norske lægeforening. 1990;111:1118-22.

10. WHO. Development of indicators for monitoring progress towards health for all by the year 2000. Geneva: WHO; 1981. 